\title{
INFORMAÇÃO EM SAÚDE BUCAL DE USUÁRIOS DE UNIDADES BÁSICAS DE SAÚDE
}

\section{BEATRIZ LOUREIRO SANTOS*; CAMILA KAORI VATANABI; KARINE LAURA CORTELLAZZI MENDES; FÁBIO LUIZ MIALHE}

\begin{abstract}
Resumo
Frente à escassez de estudos com instrumentos que aferem o letramento em saúde de forma mais abrangente, propõe-se verificar o nível de letramento em saúde bucal de usuários das UFS com e sem equipe de saúde bucal, e assim, possibilitar à comunidade acadêmica um diagnóstico sobre quais campos do letramento em saúde (obtenção, processamento e/ou compreensão das informações) podem ser melhorados por meio de intervenções. O objetivo deste estudo será avaliar o nível de letramento em saúde bucal de uma amostra de usuários das USF do município de Piracicaba e comparar os níveis de letramento em saúde bucal com as covariáveis associadas.
\end{abstract}

Palavras-chave: Alfabetização em Saúde, Saúde Bucal, Adulto, Educação em saúde.

\section{Introdução}

O letramento em saúde bucal refere-se a capacidade que os indivíduos têm de obter, processar e compreender as informações e serviços básicos de saúde para que possam então serem aptos a tomar decisões apropriadas para promoverem e manterem uma boa saúde bucal. Um baixo nível de letramento em saúde dificulta a comunicação do profissional de saúde com o paciente, assim como a tomada de decisão compartilhada sobre um problema. Como consequência disso, a adesão ao tratamento e o resultado deste pode ser insatisfatório. Desta forma, a compreensão do nível de letramento em saúde de um determinado indivíduo possibilita ao profissional adequar o seu vocabulário e a sua abordagem para que a qualidade do processo de cuidado em saúde obtenha melhores resultados.

Sendo assim o objetivo do trabalho, avaliar a qualidade da informação relacionada à saúde bucal de usuários adultos de ambos os sexos, entre 18 e 65 anos, de Unidades Básicas de Saúde do município de Piracicaba.

\section{Resultados e Discussão}

Para realizar a pesquisa foram selecionadas, de forma aleatória cerca de 60 usuários adultos das micros áreas de 10 Unidades Básicas de Saúde do município de Piracicaba, sendo 5 com ESB e 5 sem ESB e que apresentavam índice de exclusão social parecido para possível pareamento. Foi aplicado os instrumentos Held 14 e questionário socioeconômico, obtendo uma amostra de 505 usuários da atenção básica em saúde. A análise dos dados foi realizada por meio de estatística descritiva e apresentada em valores de médias e desvio padrão.

Analisando os dados coletados, nota-se majoritariamente a participação das mulheres tanto nas unidades com ESB quanto nas unidades sem ESB, representado por $71,71 \%$ e $71,65 \%$ e com média de idade de 37,93 e 36,65 anos de idade respectivamente, não sendo tão marcante a presença de idosos. Já em relação a escolaridade, revelou certo equilíbrio entre os grupos analisados. A maior parte dos voluntários apresentam 2o Grau completo, 203 pessoas, 98 destas nas unidades com ESB e 105 nas unidades sem ESB.

Tabela 1. Quantidade de indivíduos por amostra e distribuição segundo sexo, renda familiar e escolaridade.

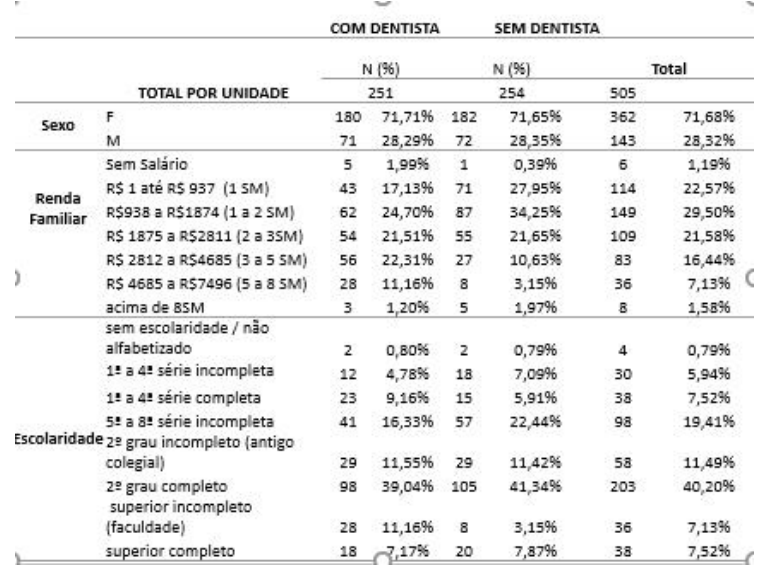

Cada item do instrumento Held 14, foi ranqueado numa escala de 5 pontos, variando de 0 a 4 , onde elevados escores indicam mínimas dificuldades de executar funções (alto LSB) e baixos escores indicam capacidades muito limitadas de executar funções (baixo LSB). As respostas foram dicotomizadas em baixo letramento ("com dificuldade" ou "muito difícil") e alto letramento ("sem dificuldade" ou" um pouco difícil").

Obtivemos uma média no escore da amostra com ESB de 37,97 com desvio padrão de 10,49 e na amostra sem ESB de 36,23 e desvio padrão 11,23 respectivamente. Lembrando que o escore máximo do instrumento é 56, representando o melhor nível de letramento em saúde bucal.

Considerou-se um nível de significância de 5\% e a análise foi realizada no programa Bioestat 5.3. Não foi observada diferença estatisticamente significativa na média geral do instrumento HeLD-14 entre os adultos em USB com ou sem DHT ( $p=0,3163)$.

\section{Conclusões}

A presença de ESB pode ser um importante determinante no acesso aos serviços odontológicos e na saúde bucal da população. Entretanto, estes achados devem ser confirmados em uma amostra maior e por meio análises mais robustas.

Baron RM, Kenny DA. The moderator-mediator variable distinction in social psychological research: conceptual, strategic, and statistical considerations. J Pers Soc Psychol. 1986;51:1173-82. Barros A, Hirakata V. Alternatives for logistic regression in cross-sectional studies: an empirical comparison of models that directly estimate the prevalence ratio. BMC Med Res Methodol. 2003;3:21. 